\title{
NEGRITUD, INDIGENISMO Y NACIONALISMO EN EL SUEÑO DEL CELTA DE MARIO VARGAS LLOSA
}

\author{
DJIBRIL MBAYE \\ Université Cheikh Anta Diop de Dakar
}

\section{Resumen}

Este artículo se propone estudiar los conceptos de Negritud, Indigenismo y Nacionalismo en El sueño del Celta de Mario Vargas Llosa. En efecto, con esta novela, el escritor peruano parece desenterrar estos movimientos sociopolíticos y literarios para convocar un nuevo juicio del colonialismo o neocolonialismo en África, América Latina y Europa. El artículo analiza este discurso anticolonial y antiimperialista, pronunciado primero por el protagonista y detrás de él por el propio autor, y sobre todo muestra la relación intrínseca que los tres conceptos mantienen entre sí en la trama novelesca. Tras una definición de los conceptos, el análisis resalta la denuncia de una dominación y de una opresión y la reivindicación de un nuevo humanismo.

Palabras clave: Negritud, indigenismo, nacionalismo, colonialismo, humanismo.

\section{NEGRITUDE, INDIGENISM AND NATIONALISM IN EL SUEÑO DEL CELTA BY MARIO VARGAS LLOSA}

\begin{abstract}
This article aims to study the concepts of Negritude, Indigenism and Nationalism in El sueño del celta by Mario Vargas Llosa. Indeed, with this novel, the Peruvian writer seems to dig out these sociopolitical and literary movements in order to convene a new judgement of colonialism or neocolonialism in Africa, Latin America and Europe. This article analyses this anticolonial and anti-imperialist discourse, pronounced first by the protagonist and behind him by the author himself, and particularly shows the intrinsic relationship among these three concepts in the fictional plot. After defining the concepts, the analysis insists on the denunciation of the domination and oppression and the vindication of a new humanism.
\end{abstract}

Keywords: Migrant, Negritude, indigenism, nationalism, colonialism, humanism. 


\section{InTRODUCGión}

La narrativa de Mario Vargas Llosa, que ha surcado fatigosamente los derroteros históricos, políticos y sociales de la nación peruana e hispanoamericana, inaugura la primera década del nuevo milenio con novelas que suman sus voces al coro mundial de la condición humana. La más destacada, y que le permite además obtener el Premio Nobel, es sin duda El sueño del celta (2010). La novela, que cuenta la odisea, en plena fiebre del caucho, del irlandés Roger Casement (quien explora un Congo desgarrado por las iniquidades del Imperio de Leopoldo II, una Amazonía ensangrentada por las malignidades de la Compañía Peruana de Julio Arana, antes de caer en un nacionalismo que le conduce a la horca), desentierra conceptos que han teñido política e ideológicamente el siglo xx y que son: negritud, indigenismo y nacionalismo.

En un momento en el que estos conceptos parecen ya ser superados y sepultados por la crítica en los escombros de la literatura y de la historia (sobre todo para los dos primeros), el escritor peruano rescata estas larvas ardientes convocando así un nuevo juicio del colonialismo y del imperialismo partiendo de tres áreas geográficas: África (el Congo Belga), la Amazonía (el Putumayo) y Europa (Irlanda). Mediante este triple escenario y la vida polémica del irlandés Roger Casement, el autor invita a una radiografía de la condición humana y una relectura descolonial y postcolonial tardía.

Así, este artículo quiere sumarse a este llamamiento para revisitar la historia y analizar la versión de los hechos que Vargas Llosa quiere narrar en esta obra y, sobre todo, demostrar el vínculo intrínseco que estos tres conceptos mantienen entre sí. No ahondaremos en las discusiones bizantinas que han marcado estos conceptos. Los entenderemos en adelante como las condiciones de subordinación, y a veces trágicas, a las que fueron sometidos el negro, el indio y el irlandés y, sobre todo, como los discursos de reivindicación de una dignidad y justicia humanas.

\section{Negritud}

No podemos referir este concepto sin aludir primero a la doctrina política y literaria fecundada por Leopold S. Senghor, Aimé Césaire y sus coetáneos, para quienes negritud resume el conjunto de los valores de civilización de la raza negra (Senghor, 1964). Pero nos interesaremos por este concepto (como ya lo ha utilizado Alejandro Solomianski, que habla de una «negritud argentina») no solo como la expresión misma de la condición del negro como ente ninguneado y sometido, sino también como la reivindicación de una humanidad y de una existencia como sujeto con plenos derechos y el 
rechazo de esa condición de inferioridad. Como reminiscencia del origen de esta ideología, Leopoldo Zea (1978: 26) nos recuerda que:

Negritud es un concepto que nace del mismo hombre que ha sufrido dominación y discriminaciones en nombre de la supuesta superioridad del hombre que no es negro sobre el que tiene la piel de este color. Es este hombre negro, y en una determinada situación histórica, entre las dos grandes guerras mundiales, el que crea el concepto que enarbolará frente al hombre blanco y discriminador. Un afroamericano y un africano, Aimé Césaire y Leopold Sedar Senghor, crean el concepto como expresión de la ideología de hombres y pueblos que en América y en África se niegan a seguir sufriendo dominación y enajenación de su ser, a partir de la supuesta inferioridad de los hombres que tienen un determinado color de piel.

Ahora es esta dinámica la que mueve el discurso que nos ofrece $E l$ sueño del celta. La novela, al narrar la explotación, esclavización y deshumanización de los negros en los campos de caucho por la corona belga, lanza un grito de protesta, de denuncia y de requerimiento de una ecuanimidad humana. La visita de Roger Casement en el corazón de África pone al descubierto prácticas inhumanas silenciadas, y su alegato feroz e incendiario contra el «civilizador» blanco discurre, sin duda, entre negritud y negrismo ${ }^{1}$.

La misión de Roger Casement en África consistía en «verificar sobre el terreno qué había de cierto en las denuncias sobre iniquidades cometidas contra los nativos en el Congo de Su Majestad Leopoldo II», y su sueño era «venir al África para, mediante el comercio, el cristianismo y las instituciones sociales y políticas de Occidente, emancipar a los africanos del atraso, la enfermedad y la ignorancia» (Vargas Llosa, 2010: 34, 35). Sin embargo, este sueño se derrumba a causa de una civilización europea que había transformado el Congo en un feudo de la barbarie.

En efecto, la misión civilizadora de Occidente se resume, según Roger Casement, en engaño en los contratos de recogida de caucho (los negros no sabían lo que firmaban), sobreexplotación, robo, calvario en las cárceles, torturas y castigo con el chicote (látigo de piel de hipopótamo, «una fiera más sanguinaria que el león y la cobra»). La imagen de un niño castigado por un teniente de la Force Publique (fuerza de seguridad compuesta por soldados y milicianos) durante una expedición punitiva en las aldeas refractarias es uno entre tantos casos de maltratos diarios que sufren los nativos:

${ }^{1}$ Al hablar de negrismo, pensamos en la poesía del cubano Nicolás Guillén, quien ha denunciado tajantemente esta dominación sobre el negro y al mismo tiempo ha cantado los valores de la civilización negra y el mestizaje. 
Cuando Roger Casement y su pequeña compañía de cinco cargadores y un «zanzibariano» entraron en el caserío, las tres o cuatros chozas estaban ya en cenizas y los pobladores habían huido. La excepción era ese muchacho, casi un niño, tumbado en el suelo, con las manos y pies atados a unas estacas, sobre cuyas espaldas el teniente Francqui descargaba una frustración a chicotazos. Generalmente, los azotes no los daban los oficiales sino los soldados. Pero el teniente se sentía sin duda agraviado por la fuga de todo el pueblo y quería vengarse. Rojo de ira, sudando a chorros, daba un pequeño bufido a cada chicotazo. No se inmutó al ver aparecer a Roger y su grupo. Se limitó a responder a su saludo con una inclinación de cabeza sin interrumpir el castigo. El chiquillo debía haber perdido el conocimiento hacía rato. Su espalda y piernas eran una masa sanguinolenta y Roger recordaba un detalle: cerca del cuerpecillo desnudo desfilaba una columna de hormigas (Vargas Llosa, 2010: 57).

De este horror diario de los nativos se llenan las páginas del informe de Roger Casement sobre el Congo. En efecto, su relato es un coro de voces martirizadas, de voces sin voz como diría Aimé Césaire. La recogida del caucho había conducido a la animalización de los negros. El propio responsable de la Force Publique, el Capitán Pierre Massard, le decía a Roger Casement, quien denunciaba las mutilaciones corporales y genitales: «hágales entender [a los negros] lo que son leyes y reglamentos a esos animales en dos patas» (Vargas Llosa, 2010: 88). Y después justifica las mutilaciones, porque para él, las municiones que se les daba a los soldados no eran para cazar «monos, culebras o demás animales de porquería», sino para defenderse, y "para comprobar que no malgastan las balas cazando», la disposición es «que cada vez que disparen [a un negro] le corten la mano y el pene al que han disparado».

Así, los nativos aparecen con manos trituradas, con heridas en las nalgas, las piernas y las espaldas. Aldeas enteras estaban quemadas, pueblos diezmados y mujeres encarceladas en penosas condiciones en lo que se llamaba maison d'otages ('casa de rehenes'). El incumplimiento de las cuotas fijadas y la huida (deserción) eran castigados de manera severa. El ejemplo de esa brutalidad es la aldea de Walla. Un destacamento de treinta soldados de la Force Publique había entrado en la aldea, lo que provocó la huida de los nativos. Pero cuando se les aseguró de que no les pasaría nada, regresaron y «los soldados cayeron sobre ellos. Hombres y mujeres fueron atados a los árboles y azotados. Una embarazada que pretendía alejarse para ir a orinar fue matada de un balazo por un soldado que creyó que huía» (Vargas Llosa, 2010: 97).

Pero lo que más aterrorizaba y martirizaba a los nativos era el hecho de no cumplir con la cantidad exigida. Podía llevarles a situaciones tan extremas como la venta de sus hijos para satisfacer una demanda a veces imposible. El narrador cuenta el caso de la aldea Walla después de ese castigo colectivo: 
Cuando, pocos días después de esta ocurrencia, el padre Hutot llegó a Walla se encontró con un espectáculo atroz. Para poder cumplir con las cuotas que adeudaban, las familias de la aldea habían vendido a hijos e hijas, y dos de los hombres a sus mujeres, a mercaderes ambulantes que hacían la trata de esclavos a ocultas de las autoridades. El trapense [padre Hutot] creía que los niños y las mujeres vendidos debían ser al menos ocho, pero acaso eran más. Los indígenas estaban aterrorizados. Habían enviado a comprar caucho y alimentos para cumplir con la deuda, pero no era seguro que el dinero de la venta alcanzara (Vargas Llosa, 2010: 97).

Esta relación de horrores que la novela saca a la luz mediante la misión de Roger constituye, para nosotros, un evidente grito de denuncia de lo que el propio Casement califica de «maldad institucionalizada». Por eso, Venco Kanev (2017: 86) habla de «salvajismo institucionalizado» antes de sentenciar que «la novela El sueño del celta mete el dedo en la llaga. Es una denuncia contundente del régimen colonial y neocolonial, de la explotación despiadada de los pueblos africanos e indígenas de América Latina». El propio Casement tras oír estos horrores confiesa, recordando el homo homini lupus de Hobbes: «ahora ya creo todo lo malo y terrible que me cuentan. Si algo he aprendido en el Congo, es que no hay fiera más sanguinaria que el ser humano» (Vargas Llosa, 2010: 98).

Cuando hablamos de negritud, nos referimos no solo a esta feria de desgracias en la que está expuesto el pueblo negro, sino también a este discurso denunciador de una esclavización maquillada a través de la explotación del caucho. En el Congo, propiedad privada de Leopoldo II, transcurría un colonialismo devastador sobre el que volaba el espectro de la esclavitud. Por eso afirma Juan Álvarez Cobelas (2015: 101) que «el Congo constituía la joya de la corona sobre la cual Bélgica edificó su modesto imperio, con unos comienzos claros de explotación cuasi-esclavista sobre la población y que evolucionó hacia un régimen paternalista».

La mirada denunciadora de una atroz subordinación que Mario Vargas Llosa pone de relieve a través de la figura del irlandés Roger Casement nos lleva a hablar de negritud vargallosiana. En efecto, la novela es la crónica de un saqueo y de una sangría humana, resultado de una misión civilizadora que no era más que una colonización despiadada, que consideraba al negro como un sujeto sin alma de una raza inferior. Pero este es el verdadero espíritu de la negritud: denuncia y alegato y lucha por una raza huérfana de la Historia y reivindicación de un humanismo. La lectura que Zekeh Gbotokuma (2010: 130) hace de la negritud senghoriana cuaja perfectamente con lo que venimos mostrando:

Pour Senghor et ses compagnons du mouvement, la Négritude est avant tout un thème de combat; elle est une lutte contre le racisme et l'inégalité, 
refus de l'oppression et révolte contre ce qu'Aimé Césaire appelle «le réductionnisme européen», la conquête d'une fraternité nouvelle plus étendue. La Négritude se propose comme un modèle culturel et un modèle de l'humanisme $\mathrm{du} \mathrm{xx}^{\text {ème }}$ siècle.

[Para Senghor y sus compañeros del movimiento, Negritud es antes de nada un tema de combate; es una lucha contra el racismo y la desigualdad, rechazo de la opresión y revuelta contra lo que Aimé Césaire llama «reduccionismo europeo», la conquista de una fraternidad nueva, más extendida. La Negritud se propone como un modelo cultural y un modelo del humanismo del siglo $\mathrm{xx}$.

Desde este mismo ángulo, se puede leer la novela como un discurso descolonizador (o anticolonialista) porque el propio autor parece sentar de nuevo al colonialismo en el banquillo de los acusados, valiéndose del juicio de Roger Casement quien sentencia sin piedad: la colonización es una aberración y la culpa de la tragedia de tantos pueblos.

Así, hablar de negritud en El sueño del celta es percibir la historia del protagonista Roger Casement como una reminiscencia de la multisecular historia trágica del negro a quien se le parece negar su humanismo. La postura desde la que Roger Casement denuncia la situación del Congo es la de una «negritud blanca» fecundada desde Europa. Si en general el discurso de la negritud ha sido siempre armado por africanos y afrodescendientes, esta vez la acusación irradia desde el propio Centro donde había nacido toda esa problemática. La voz de Casement es como una nota disonante de este coro colonialista europeo. De este modo, mediante El sueño del celta, Vargas Llosa da voz al sujeto europeo que no se reconoce en la misión civilizadora que se pretendía llevar a África a través de la colonización, un sujeto europeo mejor colocado para denunciar esta tragedia llamada colonización. Las voces de Casement, de Vargas Llosa, de Senghor y de Césaire se superponen y muestran que la condición humana es una y universal; y El sueño del celta viene a expresarlo de manera simbólica.

La novela parece inscribirse en una literatura antropológica y de protesta, una novelística de contesta y reivindicación que intenta socavar la supremacía de una quimérica civilización (traída para los bárbaros), que no era sino pretexto para sentar y bendecir un imperialismo y un capitalismo que han dejado como resultado, parafraseando a Eduardo Galeano, «las venas abiertas de África negra». Tanto Roger Casement como Vargas Llosa han firmado, a través de El sueño del celta, un manifiesto de la negritud, que también servirá después de plataforma para el hermano de la otra orilla del Atlántico: el indigenismo. 


\section{INDIGENISMO}

El viaje del protagonista Roger Casement a la Amazonía para averiguar las atrocidades que se cometían sobre los indios en El Putumayo constituye la segunda parte de la novela. El discurso denunciador de las condiciones de vida y trabajo infrahumanas de los indios nos lleva a hablar de indigenismo. Si su origen remonta antes de las luchas por la independencia ${ }^{2}$, su máximo fervor y expresión estalla en el siglo xx. Entre sus grandes pensadores destacan Manuel González Prada, considerado incluso como pionero, y José Carlos Mariátegui desde la perspectiva marxista. En la literatura, una pléyade de escritores $^{3}$ sumó sus colores a la bandera del indigenismo, requiriendo un reconocimiento del humanismo del indígena.

Así, nos acercaremos a este concepto no solo como la expresión de la condición social del indio marginado, explotado y oprimido, sino también como la creación de un discurso denunciador de esta deshumanización y de un discurso que valoriza la cultura indígena. Generalmente, la cuestión del indigenismo está vista menos como la expresión de una problemática racial que como la de una marginación sociocultural y también económica. A diferencia del fenómeno de la negritud, donde el extranjero blanco domina y margina al negro, el indigenismo se ve como «un biculturalismo residual en el que la clase dominante margina a la cultura indígena» (Morán, 1978: 46). Es este indigenismo el que Varga Llosa ensaya en su novela, y con el que

2 Repasamos brevemente el origen de este movimiento con la aclaración de Zea (1978: 26-27): «El Indigenismo, como preocupación por valorar al indio y su cultura se hace ya patente a fines del siglo xviII, eso es, pocas décadas antes de que se inicie el movimiento de emancipación política de los países que forman la América Latina. Una preocupación que surge frente a la afirmación de naturalistas europeos tales como Jean Louis Leclerc Buffon y Cornelio de Pauw respecto a la inmadurez o decadencia de la naturaleza americana y como parte de ella la inferioridad, la degeneración y bestialidad del indio americano, con la consiguiente negación de la existencia, o simple posibilidad de una cultura india. Una negación que implicaba, obviamente, la incapacidad de los habitantes de esta América, en especial América Septentrional, para emanciparse del dominio europeo. Así lo entendieron americanos como Francisco Javier Clavijero en México, Juan Ignacio Molina en Chile, el catalán Benito María de Moxo, Hipólito Unanúe en el Perú y otros muchos historiadores y naturalistas que negaron tales tesis destacando, no sólo la pujanza de la naturaleza, de la flora y fauna americanas, sino también la capacidad del indio americano como hombre y como creador de grandes culturas».

3 Morán (1978: 48-49) afirma a propósito de la literatura indigenista: «Puede ser que el Indigenismo literario comience con "Raza de bronce" (1919) de Alcides Arguedas y con su ensayo 'Pueblo enfermo'. Según Fell en "Raza de bronce" se encuentran todos los elementos racistas de la novela indigenista; pero la falta de lo que Ciro Alegría denominaba "Adhesión al indígena". Las cimas máximas de la tendencia son, evidentemente, Ciro Alegría, Enrique Pérez Albújar, Ventura Calderón, Jorge Icaza, Miguel Ángel Asturias, Rosario Castellanos, en cierto modo Rulfo (aunque su universo pertenece en realidad a lo que se denomina "novela de la Revolución mejicana" que no es exactamente indigenista), José María Arguedas». 
nos quedamos para analizar este fenómeno. Zea (1978: 30) lo define mejor con estos términos: «no es ya la pugna entre indios y blancos, sino entre explotados y explotadores, entre campesinos y oligarquía. Entre hombres que trabajan la tierra y hombres que se aprovechan de su trabajo».

En efecto, la novela narra la historia de la explotación despiadada e inhumana de los indígenas por la Peruvian Company de Julio Arana. El informe que nos hace Roger Casement de las condiciones de trabajo de los indios (Casement, 1985) es como un largo rosario de desgracias. Los indígenas, considerados casi como gente sin alma, recogen y cargan inmensas cantidades de caucho para la Compañía bajo la vigilancia de los negros barbadenses contratados por la Compañía (y que destacan por su extrema crueldad) y la supervisión de los jefes de Estaciones. El no respeto de la cantidad exigida (además, las balanzas estaban truncadas), el retraso en la entrega, la deserción o la queja eran faltas castigadas de manera inhumana. Los casos de abusos que el periodista Benjamín Saldaña Roca había denunciado, antes de la llegada de Casement, son manifestaciones de extrema crueldad. Es el ejemplo de unos indios que no habían podido traer la cantidad que se les pedía y que habían sido castigados cruentamente:

Cerca de ochocientos ocaimas [indios] llegaron a La Chorrea a entregar las canastas con las bolas de caucho recogidas en los bosques. Después de pesarlas y almacenarlas, el subadministrador de La Chorrera, Fidel Velarde, señaló a su jefe, Víctor Macedo, que estaba allí con Miguel Loaysa, de El Encanto, a los veinticinco ocaimas apartados del resto porque no habían traído la cuota mínima de jebe - látex o caucho- a que estaban obligados. Macedo y Loaysa decidieron dar una buena lección a los salvajes. Indicando a sus capataces - los negros de Barbados - que tuvieran a raya al resto de los ocaimas con sus máuseres, ordenaron a los «muchachos» que envolvieran a los veinticinco en costales empapados de petróleo. Entonces les prendieron fuego. Dando alaridos, convertidos en antorchas humanas, algunos consiguieron apagar las llamas revolcándose sobre la tierra, pero quedaron con terribles quemaduras. Los que se arrojaron al río como bólidos llameantes se ahogaron. Macedo, Loaysa y Velarde remataron a los heridos con sus revólveres (Vargas Llosa, 2010: 156-157).

Así, no solo las condiciones de trabajo eran atroces (muchas cantidades de caucho por recoger, varias semanas o meses internados en la selva, desnutridos, endeudados, desprotegidos, separados de la familia), sino que también sufrían las brutalidades de los castigos corporales. Lo peor era que las torturas se hacían a veces por puro gusto, como viene señalado por el periodista Saldaña, que indica que «los administradores hacían aquello por escarmiento, pero también con diversión». Y añade: «les gustaba. Hacer sufrir, rivalizar en crueldades era un vicio que habían contraído de tanto 
practicar las flagelaciones, los golpes, las torturas. A menudo, cuando estaban borrachos, buscaban pretexto para estos juegos de sangre» (Vargas Llosa, 2010: 157). Un ejemplo patente de eso es el que el negro barbadense le confiesa a Roger Casement:

Había visto, una noche de borrachera, a Fidel Velarde y a Alfredo Montt, entonces jefe de la estación Ultimo Retiro, apostar quién cortaba más rápido y limpiamente la oreja de un huitoto [indio] castigado en el cepo. Velarde consiguió desorejar al indígena de un solo tajo de su machete, pero Montt, que estaba ebrio perdido y le temblaban las manos, en vez de sacarle la otra oreja le descerrajó el machetazo en pleno cráneo (Vargas Llosa, 2010: 229).

Uno de los instrumentos de tortura cruel que se utilizaba era el cepo. Una jaula estrecha en la que se metía al indio y que apretaba tanto al cuerpo, con las piernas y brazos sujetados y con mucha presión en la espalda, el estómago, el pecho, las piernas, el cuello y el brazo. Esa tortura deja casi infirme al indio.

Considerados como «caníbales»y «salvajes», los indios aparecen muchas veces «con las espaldas, las nalgas y las piernas con cicatrices» como consecuencia de las torturas. Además, muchos entre ellos aparecían también marcados con las letras de la compañía como animales. Las confesiones de los negros barbadenses (capataces y verdugos de los indios) son una muestra:

Los barbadenses me han explicado que muchos indígenas están marcados con las iniciales de la Compañía: CA, es decir Casa Arana. Como las vacas, los caballos y los cerdos. Para que no se escapen ni se los roben los caucheros colombianos. Ellos mismos han marcado a muchos (Vargas Llosa, 2010: 217).

Pero para los explotadores, los indios son simplemente animales. Este juicio de Armando Normand, jefe de la estación de Matanzas, en una discusión tensa con Roger Casement, lo confirma: «a los animales, no se les puede tratar como a los seres humanos. Una yacumama, un jaguar, un puma, no entienden razones. Los salvajes tampoco» (Vargas Llosa, 2010: 242).

El informe que Roger Casement hace de su visita en esta Amazonía peruana es como una enciclopedia de crueldades infligidas a los indios. $\mathrm{Su}$ narración es un testimonio de deshumanización de seres a quienes incluso se les niega la humanidad. Por eso, Roger Casement concluye con esta lapidaria constatación: "para ellos los indígenas amazónicos no eran, propiamente hablando, seres humanos, sino una forma inferior y despreciable de la existencia, más cerca de los animales que de los civilizados»; y deduce que «por eso era legítimo explotarlos, azotarlos, secuestrarlos, llevárselos a las caucherías, o, si se resistían, matarlos como a un perro que contrae la rabia» (Vargas Llosa, 2010: 209). 
Es en este sentido que hablamos de indigenismo vargasllosiano. En efecto, a través de la investigación de Roger Casement, el autor introduce un discurso de denuncia de un «crimen organizado» y de la miseria de la «masa campesina siniestra en su desgracia y en su abandono» (Morán, 1978: 49), una denuncia de la servidumbre y aun de la deshumanización de un ser encasillado en la periferia de la existencia.

Vargas Llosa rescata, mediante la figura de Roger Casement, una de las tradiciones del indigenismo: los no indígenas como portaestandartes del discurso indigenista. Como un "padre de Las Casa británico», Roger Casement fustiga una casi-esclavitud sustentada por una codicia apadrinada por un imperialismo despiadado. El autor pone de relieve, una vez más, la dimensión socio-histórica de su narrativa, y El sueño del celta puede considerase como un tardío manifiesto palimpsestico (discurso de Vargas Llosa sobre el de Casement) de un indigenismo posmoderno donde la voz denunciadora es la del europeo superpuesta a la del nativo peruano. Por eso, considera tal vez Zea (1978: 31) el indigenismo como «la expresión de la doble lucha interna y externa que mantienen los pueblos en esta parte del continente para poner fin a una situación de dominación, de dependencia», una situación similar contra la que se había alzado también la negritud.

\section{Dos conceptos, UnA Misma REALidad}

El viaje de Roger Casement a África y a la Amazonía ha puesto de manifiesto una situación evidente: la similitud entre las condiciones infaustas de dependencia y explotación de los negros y de los indios. La novela es una sutil equiparación de la tragedia de los indígenas africanos y americanos, un espejo que refleja las duras condiciones socioeconómicas de seres considerados como salvajes, seres «expulsados» de la Historia y de la Humanidad. La lectura que nos hace Kanev (2017: 86) resume atinadamente la cruda realidad pintada en la novela:

Lo esencial de la novela es el salvajismo del colonizador europeo aliado con los caciques locales. Del salvajismo, el concepto clave, derivan otros como la tortura, la maldad, el sufrimiento, la desesperación, la aniquilación física y espiritual del hombre, su reducción a una condición infrahumana, animal, peor que la de los animales libres.

Esta relación de desgracias que la novela pone de realce mediante el viaje de Roger Casement hace reminiscencia a los movimientos de la negritud y del indigenismo, ya que los dos se han alzado para denunciar la opresión de los indios y negros, y «ambas literaturas contestan, reivindican, desde una marginación social y cultural establecida conforme a criterios de raza» 
(Morán, 1978: 37). Pero es de este marco incluso de donde han nacido los movimientos, por lo que afirma Zea (1979: 25):

Negritud e indigenismo son conceptos ideológicos que tienen su origen en una situación que es común a los hombres de África negra y Afroamérica por un lado y de Latinoamérica o Indoamérica por el otro: la situación de dependencia. En uno y en otro caso expresa la toma de consciencia de una situación de marginación y subordinación que se pretende cambiar.

La recogida de caucho había convertido a los indígenas negro y americano en damnificados de un sistema colonial que hasta les negaba su humanidad. Tanto indios como negros estaban considerados como animales, «animales de dos patas» para los negros, y animales como la yacumama, el jaguar, el puma, para el indio. Es en este sentido que recuerda Zea (1978: 25) que «lo negro y lo indígena vienen a ser expresión de lo subhumano. Y por serlo, un simple y puro instrumento de quienes se consideraban a sí mismos la máxima expresión del Hombre».

Después de su viaje al Congo, su estancia en el Putumayo se había convertido en un facsímil del infierno africano, e incluso peor. Nada más constatar los horrores que sufren los indígenas americanos («latigazos, encierro en el cepo o potro de tortura, corte de oreja, de narices, de manos, de pies hasta asesinatos; ahorcados, abaleados, quemamos o ahogados») Roger recuerda al Congo: «pese a estar tan lejos, pensó una vez Roger Casement, el Congo y la Amazonía estaban unidos por el cordón umbilical. Los horrores se repetían, con mínimas variantes, inspirados por el lucro, pecado original que acompañaba al ser humano desde su nacimiento» (Vargas Llosa, 2010: 158).

En realidad, la Amazonía y el Congo eran cara y cruz de una misma situación inhumana. Al escuchar las confesiones de los capataces, Roger no puede separase de las pesadillas del Congo: «El Congo. La Amazonía. ¿No había pues límites para el sufrimiento de los seres humanos?» (Vargas Llosa, 2010: 163). En efecto, la similitud de ambas situaciones sociales era visible a cada paso. Pero por lo visto, el sufrimiento en la Amazonía era incluso peor. Las iniquidades sobre indígenas llevadas a cabo por los capataces y los administradores habían superado los límites de la razón humana. Roger evoca la sanguinaria figura de Armando Normand (verdugo de los indios): «Roger se decía, revisando su memoria, que, entre la vasta colección de malvados que había conocido en el Congo, seres a los que el poder y la impunidad habían vuelto monstruos, ninguno llegaba a los extremos de este individuo» (Vargas Llosa, 2010: 234).

Lo más sorprendente para Roger es que a pesar de la visibilidad de los maltratos, las autoridades desmentían o relativizaban los hechos. Es el caso de Pablo Zumaeta, responsable de la Peruvian Amazon Company, interrogado 
por la Comisión. Por eso concluye el narrador: «Roger se sentía transportado en el espacio y en el tiempo al Congo. Los mismos horrores, el mismo desprecio de la verdad» (Vargas Llosa, 2010: 174).

Para Roger, el Congo se había convertido en la propia expresión de la desgracia humana. El Congo era la Amazonía, la Humanidad sufrida. Tras escuchar al padre Urrutia referir los casos frecuentes de compraventa de niñas, utilizadas como sirvientas y más tarde como esclavas sexuales, Roger exclama: «el Congo, otra vez. El Congo, por todas partes» (Vargas Llosa, 2010: 163). Y después de ver las cicatrices en los cuerpos de los indios exclama: «el Congo, sí, el Congo por doquier» (Vargas Llosa, 2010: 211).

Esta hermandad en el dolor y el sufrimiento cimienta la trama de El sueño del celta. La novela convoca una feria de las desdichas de entes bajados de su pedestal de Ser Humano. La explotación despiadada que conduce a la aniquilación de todos los derechos de existir se había convertido en la seña de identidad de la fiebre del caucho. Kanev (2017: 86) habla de «el Congo en la Amazonía y la Amazonía en el Congo» y concluye que «toda la novela cuestiona el concepto de colonialismo y el neocolonialismo, de la civilización llevada como un gran bien a los pueblos a las tribus salvajes».

Así podemos afirmar, parafraseando a Zea, que el negro y el indígena, al afirmar su negritud y su indigenismo, afirman su humanidad. Ahora bien, esta afirmación no significa rechazo sistemático al otro ni tampoco dejar de ser negro o indígena para ser el otro, sino más bien construir una Humanidad que reconozca de forma igual a todos sus hijos. Este alegato de Zea (1978: 33) a este respecto es toda una lección de humanismo:

El negro no quiere dejar de ser negro para ser blanco, como tampoco el latinoamericano dejar de ser mestizo para ser europeo o anglosajón. De lo que se trata es comulgar la cultura del blanco, la cultura europea u occidental, así como toda expresión cultural del hombre sin que por ello se deje de ser hombre concreto, negro o latinoamericano. El ser negro o el ser latinoamericano debe ser enriquecido, ampliado, nunca negado. A su vez, el otro, el blanco, el occidental, cualquier hombre, puede enriquecerse con la experiencia cultural del negro y el latinoamericano. Tal es lo que ofrece la negritud, tal es lo que ofrece el latinoamericanismo a otras culturas, la experiencia cultural del hombre en otra circunstancia o situación.

El planteamiento de la negritud y del indigenismo también constituye un discurso antimperialista y anticolonial. La Corona belga y La Compañía Arana se habían convertido en las representantes del binomio colonialismo /imperialismo. Indigenismo y negritud se han alzado contra una situación de dominación y explotación motivada por el colonialismo o sus consecuencias. Es lo que parece decir Morán (1978: 45), cuando observa que: 
Es evidente que, como literatura de la descolonización, la literatura de la negritude coincide en impulsos y vivencias con la indigenista latinoamericana que empieza por denunciar el estado de las comunidades indias como consecuencia de la colonia y termina por atacar a las grandes compañías internacionales y el empleo de los indios en los monocultivos.

En la novela, el anticolonialismo es más que evidente. La requisitoria de Roger Casement en contra de la colonización constituye la espina dorsal de la novela. Como observa Villar Dégano (2011), Roger empieza siendo un defensor de los valores de un colonialismo utópico y termina siendo, mediante sus informes demoledores, un acérrimo anticolonialista. Gran «debelador de injusticias», la experiencia trágica, hija del colonialismo y del imperialismo de la que es testigo, le recuerda a Irlanda y constituye la semilla de su nacionalismo.

Mario Vargas, a través de El sueño del celta y del personaje de Roger Casement, ha reconstruido el infame triángulo de la esclavitud, pero no desde la versión histórica sino desde un ángulo revisionista. En efecto, si se trataba antes del europeo que viajaba a África, sacaba a esclavos negros y los llevaba a América para después cerrar su ciclo de vuelta en el Viejo mundo, Vargas Llosa propone el mismo esquema Europa-África-América-Europa, pero para rescatar una acción heroica muchas veces silenciada por la Historia oficial: la tajante condena y denuncia del colonialismo y del imperialismo desde las propias filas europeas. La odisea de Roger Casement sigue las huellas del colonizador no para hacer una simple reminiscencia histórica, sino más bien para meter el dedo en la llaga y denunciar en voz alta lo que la Historia oficial se avergüenza en publicar. Mario Vargas Llosa ha encontrado en Roger Casement su personaje ideal, el que ha podido sintetizar negritud e indigenismo, África y América Latina en un humanismo europeo, que al final desemboca en un acérrimo nacionalismo.

\section{NaCionalismo}

En la novela, negritud e indigenismo desembocan en el nacionalismo. En efecto, la larga y penosa misión investigadora de las injusticias que se cometían en el Congo y en la Amazonía lleva a Roger Casement a una toma de consciencia de la situación de su tierra: Irlanda. El contacto con el sufrimiento de los negros, causado por el colonialismo, había empezado a despertar en él un sentimiento nacionalista y él comenzaba a plantear la similitud de ambos pueblos bajos varias interrogaciones:

¿No era también Irlanda como una colonia, como el Congo? Aunque él se hubiera empeñado tantos años en no aceptar esa verdad que su padre y tantos irlandeses del Ulster, como él, rechazaban con indignación. ¿Por qué 
lo que estaba mal para el Congo estaría bien para Irlanda? ¿No habían invadido los ingleses al Eire? ¿No la habían incorporado al Imperio mediante la fuerza, sin consultar a los invadidos y ocupados, tal como los belgas a los congoleños? (Vargas Llosa, 2010: 110).

$\mathrm{Su}$ contacto con la injusticia había producido en él una gran desilusión. Si al principio pensaba que la colonización era para traer a los nativos africanos el progreso mediante las «3C» (cristianismo, civilización y comercio), al final se derrumba su esperanza ante tanta crueldad infligida a los negros ${ }^{4}$. Además, tal situación aviva en él su condición de irlandés colonizado:

Allá, en el Congo, conviviendo con la injusticia y la violencia, había descubierto la gran mentira que era la colonización y había empezado a sentirse un «irlandés», es decir ciudadano de un país ocupado y explotado por un Imperio que había desangrado y desalmado a Irlanda (Vargas Llosa, 2010: 119-120).

Roger se identifica así con la condición de indígena, particularmente de congoleño. Se convierte en la voz de los congoleños maltratados. La denuncia de las iniquidades y la defensa de seres indefensos recuerdan automáticamente al lector la figura del Padre Bartolomé de Las Casas. Por eso, la mujer de Joseph Conrad, cuyo marido había escrito un libro sobre el Congo titulado El corazón de las tinieblas y considerado por Roger como «la más extraordinaria descripción de los horrores que se vivían en el Congo», le dijo a Roger que «por lo que venía haciendo a favor de los indígenas congoleses, merecía ser llamado "el Bartolomé de las Casas británico"»(Vargas Llosa, 2010: 74).

Como con los congoleses, Roger también se identifica con la causa de los indios. Los mismos horrores y la misma situación de dominación y opresión que había visto le habían convertido en ferviente adepto del anticolonialismo. Incluso para Roger, los propios irlandeses eran literalmente como los indios de la Amazonía:

Los irlandeses somos como los huitotos, los boras, los andoques y los muinanes del Putumayo. Colonizados, explotados y condenados a serlo siempre si seguimos confiando en las leyes, las instituciones y los Gobiernos de Inglaterra para alcanzar la libertad (Vargas Llosa, 2010: 239).

4 Esto puede ser ilustrado en la cita siguiente, en la que Roger y su amigo Herbert comparten la misma opinión sobre la verdadera intención de la colonización: «Herbert fue de las escasas personas a quien Roger confió su decepción con Stanley, con Leopoldo II, con la idea que lo trajo al África: que el Imperio y la colonización abrirían a los africanos el camino de la modernización y el progreso. Herbert coincidió totalmente con él, al comprobar que la verdadera razón de los europeos en el África no era ayudar al africano a salir del paganismo y de la barbarie, sino explotarlo con una codicia sin límites para el abuso y la crueldad» (Vargas Llosa, 2010: 345). 
La situación del Congo y del Putumayo no sólo había fecundado su nacionalismo, sino que, además, le había inspirado algo más revolucionario: el levantamiento de los irlandeses contra el Imperio británico. Para Roger la lucha armada se había convertido en la única vía de salvación de los irlandeses. Por eso afirma que «no debemos permitir que la colonización llegue hasta castrar el espíritu de los irlandeses como ha castrado el de los indígenas de la Amazonía. Hay que actuar ahora, de una vez, antes de que sea tarde y nos volvamos autómatas» (Vargas Llosa, 2010: (2010: 247). En efecto, para él, la colonización había oxidado la mentalidad de los indígenas quienes no pensaban en ninguna ocasión en revelarse contra esta injusticia. Por eso, la sublevación se había vuelto su credo nacionalista, en su programación de liberación de Irlanda y en su obsesión contrariamente a los indios:

Desde que había llegado al convencimiento de que sólo una acción resuelta, una rebelión, podía librar a su patria de «perder el alma» a causa de la colonización, como les había pasado a los huitotos, boras y demás infelices del Putumayo, ardía de impaciencia por volcarse cuerpo y alma en preparar aquella insurrección que acabara con tantos siglos de servidumbre para su país (Vargas Llosa, 2010: 257).

La emancipación de Irlanda ya era «el designio excluyente de su vida» y Roger movilizaba toda su inteligencia y su energía para ello. Su visión nacionalista ya se resumía en este refrán que él mismo repetía muchas veces: «las desgracias de Inglaterra son las alegrías de Irlanda» (Vargas Llosa, 2010: 328). Y como la Compañía de Arana está arruinada tras sus denuncias, su lucha se concentra en los indígenas irlandeses: «ahora, debía ocuparse de otros indígenas, los de Irlanda. También ellos necesitaban librarse de los "aranas" que los explotaban, aunque con armas más refinadas e hipócritas que las de los caucheros peruanos, colombianos y brasileños» (Vargas Llosa, 2010: 378).

Así, Roger Casement regresa a Inglaterra, renuncia a su cargo de diplomático y dedica exclusivamente su labor a la emancipación del Eire. En contacto con los movimientos nacionalistas irlandeses, realiza muchas actividades entre las que destaca un viaje a Alemania, cuyo objetivo era conseguir armamento para los revolucionarios irlandeses. Detenido a su regreso, es acusado de traición, condenado a muerte y ahorcado el 3 de agosto de 1916.

La novela muestra, a través de esta figura, los horrores del colonialismo y neocolonialismo, pero sobre todo cómo los idearios defendidos por el indigenismo y más tarde la negritud han fecundado el pensamiento de uno de los más destacados líderes revolucionarios y nacionalistas irlandeses. La vida de Roger Casement narrada en la novela es un cauce de distintas orillas (africana, latinoamericana y europea) que bañan las oscuras facetas 
de la condición humana. En suma, la historia sincrética de Roger Casement es la metáfora de un juicio convocado por el indigenismo, la negritud y el nacionalismo contra la colonización y el imperialismo, y El sueño del celta, la parábola de tribunal donde oficia el incansable escribano y escribidor: Mario Vargas Llosas. En efecto, este es el rol que se ha asignado Vargas Llosa a través de la novela: rescatar la verdadera figura de Roger Casement injustamente eclipsada por una Historia oficial imperialista. En el epílogo de la novela, como para decir abiertamente lo que piensa, el autor denuncia esa conjura histórica organizada contra el que está considerado como «uno de los grandes luchadores anticolonialistas y defensores de los derechos humanos y de las culturas indígenas de su tiempo y un sacrificado combatiente por la emancipación de Irlanda» (Vargas Llosa, 2010: 449). El propio autor lamenta también esta injusta realidad: «ni en el Congo ni en la Amazonía, ha quedado rastro de quien tanto hizo por denunciar los grandes crímenes que se cometieron en estas tierras en los tiempos del caucho» (Vargas Llosa, 2010: 450). Es lo que ha llamado nuestra atención a leer la novela. El Congo es la reminiscencia de la negritud, la Amazonía la del indigenismo e Irlanda la del nacionalismo. Y como enseñanza: el nacionalismo como hijo de la negritud y del indigenismo.

\section{Conclusión}

Mario Vargas Llosa ha reflejado, a través de El sueño del celta, la cara hedionda del colonialismo. Como un evangelio de una nueva-negritud y de un neo-indigenismo, la novela lanza un grito de protesta contra la deshumanización del negro y del indio. La misión de Roger Casement, una operación catártica de excoriación de una civilización cimentada en la barbarie, rescata los conceptos de negritud e indigenismo, dos derroteros que desembocan en el nacionalismo. El sueño del celta representa, a este efecto, un discurso sobre la condición humana y propone un ingenioso sistema de vasos comunicantes donde un congoleño, un peruano y un irlandés (un negro, un indio y un celta) comparten la misma mesa de desgracias. Pero la mejor lección que transluce a través de esta novela, escrita palimpsésticamente por Roger Casement y Mario Vargas Llosa, es que la verdadera patria del ser humano, a la imagen de Casement, debe ser la humanidad, donde libertad y justicia constituyen los colores de la bandera que debe ondear en cada sociedad.

\section{BibLIOGRAFÍA}

Álvarez Cobelas, J. (2015): África Saqueada. La Occidentalización y sus trampas. Estados fallidos y caridad internacional. Madrid, Queimada.

Casement, R. (1985): Putumayo. Caucho y sangre. Relación al parlamento inglés (1911). Quito, Abya-Yala. 
Gвотокuma, Z. (2010): «Senghoritude: le credo senghorien comme défi à la mondialisation». En Animan Akassi, C. y Lavou Zoungbo, V. (eds.): Discursos poscoloniales y renegociaciones de las identidades negras. África, América, Caribes, Europa. Perpignan, PUP, págs. 121-139.

Kanev, V. (2017): «El salvajismo institucionalizado en El sueño del celta de Mario Vargas Llosa». América, 50, págs. 85-94 (en línea: <http://america.revues.org/1850> [consulta: 30 de abril de 2018]).

MorÁn, F. (1978): «Literatura indigenista sudamericana y doctrina literaria de la "Negritude": semejanza y diferencias». En Durand, R. (ed.): Négritude et Amérique Latine. Dakar, Les Nouvelles Editions Africaines, págs. 37-51.

Senghor, L.S. (1964): Liberté I: Négritude et Humanisme, Paris, Edition du Seuil.

Solomiansky, A. (2003): Identidades secretas: la negritud argentina. Rosario, Beatriz Viterbo.

Vargas Llosa, M. (2010): El sueño del celta. Madrid, Santillana Ediciones Generales.

Villar Dégano, J.F. (2011): «Breves notas a El sueño del celta de Mario Vargas Llosa, al hilo de otras observaciones de su ensayo La orgía perpetua». Revista Cálamo FASPE, 57, págs. 53-58.

Williams, G.W., Casement, R. y Doyle, A.C. (2010): El crimen del Congo. Trad. S. Carral Martínez y L.F. Díaz. La Coruña, Ediciones del viento.

ZEA, L. (1978): «Negritud e indigenismo». En Durand, R. (ed.): Négritude et Amérique Latine. Dakar, Les Nouvelles Editions Africaines, págs. 25-36. 